\title{
DESIGN DE SUPERFÍCIE E BIÔNICA: O CAQUI COMO ELEMENTO CRIATIVO NO DESENVOLVIMENTO DE ESTAMPAS PARA A INDÚSTRIA TÊXTIL
}

\author{
Érica Boeing \\ Faculdade SATC \\ ericaboeing@yahoo.com.br \\ Diego Piovesan Medeiros \\ Faculdade SATC/ UFSC \\ diego.piovesan@gmail.com \\ Marília Matos Gonçalves \\ UFSC \\ marilinhamt@gmail.com
}

\begin{abstract}
Resumo: O presente artigo tem como objetivo o desenvolvimento de estampas referenciadas pela natureza para a indústria têxtil, tendo como objeto de análise, o fruto Caqui. O estudo aborda o valor do Design de Superfície para a indústria têxtil, assim como a importância da originalidade na produção criativa, tendo em vista a competitividade no mercado. Para tanto, é realizado um embasamento teórico baseado no estudo biônico do objeto de análise, realizado por meio de imagens capturada, possibilitando por meio de uma metodologia projetual, o desenvolvimento de padrões baseados em elementos da natureza. Tendo como forma de estimulação criativa, serão apresentados neste artigo dois resultados obtidos com a realização do processo criativo.
\end{abstract}

Palavras-chave: Design de Superfície; Biônica; Metodologia, Caqui.

\begin{abstract}
This paper aims at the development of prints referenced by nature for the textile industry, with the object of analysis, the persimmon fruit. The study addresses the value of the Surface Design for the textile industry as well as the importance of originality in creative production, with a view to market competitiveness. Thus, a theoretical framework based on the bionic study the object of analysis, conducted through captured, allowing through a methodology projetual images is carried out to develop standards-based elements of nature. Having as a form of creative, will be presented in this paper two results obtained with the creative process.
\end{abstract}

Keywords: Surface Design; Bionics, Methodology, Persimmon. 


\section{INTRODUÇÃO}

Design de Superfície é uma área de atuação do design que ocupa espaço singular, pois fundamenta e qualifica os projetos por meio de ferramentas projetivas próprias, tornando a superfície uma estrutura com propriedades visuais, táteis, funcionais e simbólicas, lidando mais com uma ordem estética do que funcional.

Dentre as diversas possibilidades criativas e de pesquisa visual possíveis para se desenvolver um projeto de design de superfície, destaca-se a Biônica, sendo a ciência que estuda estruturas e sistemas encontrados na natureza. Bertoline (2009) coloca que a biônica se baseia em observações e investigações de fenômenos naturais, possibilitando a documentação de material de importante utilidade no desenvolvimento de projetos de design, aproximando as soluções técnicas e formais encontradas, por meio da metodologia aplicada durante a elaboração do projeto, ao fenômeno natural estudado.

Como no design de superfície o senso estético tem um peso considerável, são muitas as vantagens oferecidas pela biônica, que coloca a disposição do designer a natureza como fonte de inspiração de ideias. Assim, verificando a importância da utilização de uma metodologia criativa, pretende-se nesta pesquisa, buscar respostas à seguinte problemática: Como os elementos naturais podem ser referências para estampas aplicadas na indústria têxtil? Com a problemática já delimitada, chega-se ao objetivo geral que é criar estampas inspiradas na exploração dos elementos naturais, por meio do desenvolvimento de padrões para indústria têxtil, a partir do estudo da Biônica e do Design de Superfície.

\section{DESIGN DE SUPERFÍCIE E O SETOR TÊXTIL}

De modo geral, Rubim (2010) afirma que no design e, consequentemente, no Design de Superfície, o trabalho conceitual e projetual estão em destaque, e devem atender às expectativas do mercado, pois estão vinculadas às tendências e devem também estar sujeitas e acompanhando o desenvolvimento tecnológico. É uma área em ascensão e requer do designer conhecimentos originários de áreas distintas, uma vez que, com o avanço da tecnologia, há maior liberdade de criação.

De acordo com Pereira, Ruthschilling e Silva (2010, p. 04), “[...] o desenho projetual de uma superfície será responsável, em grande parte, pela troca de significados com o usuário [...]", sendo então considerado um elemento de comunicação do produto. Ainda conforme os autores, o significado dos símbolos depende da capacidade do designer de identificar as necessidades, requisitos, o contexto sociocultural e o estilo de vida da sociedade para transpor, por meio de funções práticas e estéticas do produto, signos que tornaram o mesmo um objeto de desejo e identificação.

Ruthschilling (2008) afirma que projetos relacionados à constituição e/ou tratamento das superfícies passam por uma revisão, pois há uma mudança constante nos processos de fabricação, atuando como limitadores da criação. Desta maneira cabe ao designer a capacidade de entender às necessidades do indivíduo e usar da imaginação e criatividade para elaborar objetos e ambientes que estão a sua volta. Isso se fortalece ao entrar no mundo têxtil e de moda.

O produto têxtil é a transição do íntimo para o externo, o tecido revela a identidade de quem o usa, mostra seus sentimentos, valores, história para toda a 
civilização. Pezzolo (2007) afirma que verificando as raízes do vestuário ao longo do tempo nas diversas civilizações, conclui que ela expressa a vida e a cultura dos povos, e sua evolução se baseou nas necessidades materiais e sociais do homem.

Dessa forma, o desenho de padrões para superfície percorreu um caminho iniciado com técnicas artesanais antigas, chegou à evolução tecnológica de materiais e processos na época contemporânea, e hoje se estabelece como campo investigativo abrangente e um recurso diferenciador no projeto de diversos produtos (MINUZZI e OLIVEIRA, 2008).

Para Calderón (2010, p.03), "[u]m projeto de design bem elaborado permite que os valores sejam agregados a eles e, igualmente, ás empresas e serviços.", sendo que este valor é implantando por meio dos elementos visuais estéticos, que caracterizam e personalizam cada produto. Baseado em estudos Levinbook (2008), Lipovetsky (1989) afirma que a cada lançamento de coleção, tendências são lançadas em busca de mudanças, esta que é da própria natureza da moda, está sempre em busca do novo.

O Design de Superfície da vida à moda, um mercado muito completo, cheio de possibilidades de atuação, trabalhando como complemento do trabalho do designer de moda. Dentre os designers que estão se destacando no desenvolvimento do Design de Superfície junto ao ramo têxtil, pode-se citar Goya Lopes, designer têxtil que está fazendo sucesso em Roma e Nova York com sua grife Didara. As roupas e tecidos desenvolvidos por ela apresentam cores fortes e motivos afro-brasileiros. Os seus desenhos são feitos depois de muita pesquisa, representam cenas de calçadas ou representações de animais, e até mesmo figuras abstratas.

Outro designer que atua constantemente no desenvolvimento de padrões para o Design de Superfície é Wagner Campelo, seu trabalho é diversificado e eclético, prefere trabalhar com estampas que aliam formas e cores numa linguagem simples e alegre. Exemplos de seu trabalho podem ser vistos na figura 1.
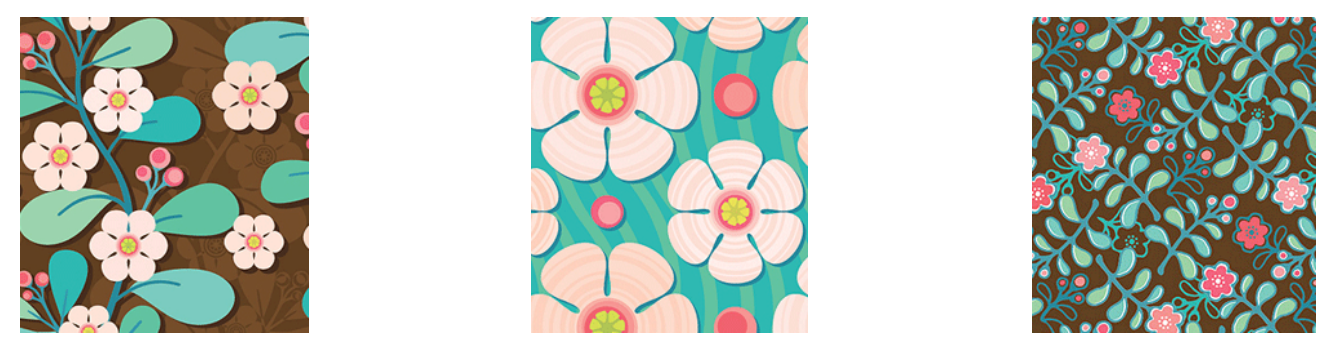

Figura 1 - Estampas coordenadas de Wagner Campelo

Fonte: http://www.wagnercampelo.com/portfolio_coordenados.htm, acessado em 14/02/2014

Campelo trabalha com uso de fotografias, na criação de padrões pouco comuns. Alguns de seus projetos acabam trabalhando com elementos provenientes ou inspirados da natureza. Segundo Pezzolo (2007), há muitos séculos a natureza vem sendo fonte de inspiração, tanto de forma fiel ou estilizada pelo homem em seus tecidos. É o mais simples e puro modelo para a criação de desenhos, as formas e cores se mostram prontas e o homem as transforma em estampas com interpretações pessoais.

\section{BIÔNICA COMO PROCESSO CRIATIVO NO DESIGN}

O processo criativo no desenvolvimento de um produto exige cada vez mais do designer, este está em uma constante busca de soluções cada vez melhores e 
inovadoras para que se alcance o objetivo do projeto que lhe for proposto. Neste contexto, Hsuan-An (2002) cita que há necessidade constante de estímulos da criatividade e da percepção estética, assim como reflexões e críticas durante o desenvolvimento de determinado trabalho, para que o mesmo se desenvolva e se solucione da melhor maneira.

Dessa forma, a relação com os elementos da natureza, segundo Silveira et al (2010, p.02), "[...] pode ser uma maneira de descobrir novos princípios, formas, processos e estruturas de novos produtos.". A utilização da natureza como fonte de referência no processo criativo, no design, está diretamente ligada à Biônica. Hsuan-An (2002) segue o mesmo raciocínio quando diz que a arquitetura e o design devem desfrutar das vantagens oferecidas pela Biônica, pois os elementos naturais são fontes inspiradoras e revelam importantes ideias.

Ideias importantes e inovadoras estão surgindo de pesquisas sobre os sistemas e propriedades naturais, devido ao fato que a análise Biônica facilita e estimula a capacidade de percepção de detalhes e princípios encontrados na sua estrutura (SILVEIRA et al, 2002). Detanico, Teixeira e Silva (2010), colocam que os recursos encontrados na natureza podem contribuir durante o processo criativo de um projeto, tanto com semelhanças quanto por meio de seus padrões geométricos e matemáticos, pois estas são características presente na composição dos seres humanos, animais e vegetais.

Munari (2008, p.330) afirma que "[a] biônica estuda sistemas vivos, ou semelhantes aos vivos, para descobrir processos, técnicas e novos princípios aplicáveis à tecnologia.". Silveira et al (2010) complementa dizendo que é o estudo dos sistemas e organizações naturais visando às funções, estruturas e formas para aplicar na solução de projetos por meio da tecnologia, de objetos e de sistemas de objetos.

A análise biônica, conforme Munari (2008), torna-se o ponto de partida e fonte de inspiração na busca por soluções projetuais. A análise seja de um fruto, de um inseto ou até mesmo da resistência da casca de um ovo é útil ao conhecimento e estimula a criatividade. Assim, as alternativas criativas e experimentais geradas por um método de investigação e caminhos não controlados permitem soluções inusitadas e inovadoras (BERTOLINE, 2009).

Silveira et al (2010) analisa que, conforme se observam os elementos naturais, por meio de suas formas e cores, por exemplo, encontramos soluções simples para um projeto, sendo que a natureza pode ser interpretada de diversas maneiras, servindo de fonte de inspiração, onde a criatividade do designer é o limite. Os resultados, conforme os autores irão variar de acordo com a técnica utilizada, o estudo da Biônica deve ser uma referência na pesquisa de técnicas e materiais diversos.

Ir à natureza é verdadeiramente ir à fonte, as estruturas e cores encontradas na mesma são fontes de referência e inspiração (BASSO e RUTHSCHILLING, 2010), e diante de um elemento natural deve haver um processo de seleção e análise para que as formas sejam reduzidas a menores símbolos. Doczi (1990) complementa que a natureza é feita de padrões, os quais ditam a ordem dos elementos no mundo.

No método da analogia e relações frequentes com a natureza, é possível encontrar soluções para concepção de projetos. Para Detanico, Teixeira e Silva (2010, p.105) "O Biomimetismo ou a Biônica são abordagens tecnologicamente orientadas para aplicar as lições de design da natureza buscando solucionar os problemas do homem". Os estudos biomiméticos são embasados nas soluções naturais de projetos, 
entendendo as geometrias e funcionamentos dos mesmos, na busca da melhor aplicação e do menor gasto de energia, assim o biomimetismo não tem como intuito extrair algo da natureza e sim aprender com ela.

\section{METODOLOGIA PROJETUAL CRIATIVA}

Todo e qualquer projeto de design, deve ser elaborado utilizando um método, sendo que cada novo objeto de estudo resulta em um processo de desenvolvimento, tendo como objetivo atingir o melhor resultado. Levando em consideração que o método pode ser modificado pelo designer, a fim de que o mesmo estimule sua criatividade e a descoberta de novos meios ao longo do processo.

Acredita-se que, para se desenvolver um projeto de design, é necessário partir de um problema. No caso do estudo aqui apresentado, a necessidade cada vez maior que as indústrias têm em inovar e propor soluções criativas aos clientes, visto que na indústria têxtil, a cada estação, novas coleções são lançadas no mercado estimulando o consumo. Torna-se necessário então a definição dos objetivos que levaram a encontrar a solução do problema, sendo esta feita por meio da coleta de informações sobre tendências de moda e sua análise. Parte-se então para a análise do objeto a ser estudado, iniciado com escolha do elemento da natureza a ser trabalhado e seu estudo científico, sua coleta e a separação dos materiais a serem estudados.

Posteriormente, tem início o processo de geração de alternativas, observando então o objeto tanto a "olho nu", como microscopicamente. Então é realizada a documentação das imagens, feita a escolha delas e elaboração dos desenhos preliminares, assim como a seleção de cores a serem aplicadas na estampa. Finalmente, desenvolve-se a criação dos módulos e geração de padrões com os dados obtidos ao longo do processo.

\section{O CAQUI: UMA ANÁLISE POR MEIO DA BIÔNICA}

Consciente que as formas da natureza exercem, segundo Hsuan-Na (2002), influência e sensibilidade sobre a percepção, e verificando a sua utilização no desenvolvimento de estampas para a indústria têxtil, torna-se necessário realizar uma análise do fruto escolhido por meio da biônica. $O$ autor afirma que, o estudo só pode ser realizado se baseado em informações concretas das características e propriedades do objeto estudado, pois estes fatores irão contribuir para avaliar os critérios e parâmetros a serem utilizados em cada etapa do projeto. Desta forma, por mais simples que o modelo biológico for, pode ser rico nas características a serem exploradas.

No caso deste estudo exploratório, o modelo biológico a ser analisado é o fruto Caqui, colhido do pé ainda em estágio de maturação. Originário da Ásia, mais precisamente da China, o caqui é proveniente do caquizeiro, que tem seu nome científico denominado Diospyros kaki L.f.. Há séculos foi levado para o Japão, conforme Edagi e Kluge (2009), hoje é cultivado em todo o mundo. A cultura do caqui foi introduzida no Brasil, por imigrantes japoneses, no final do século XIX, que segundo os autores, rapidamente se expandiu, considerando a adaptação às condições brasileiras, principalmente no que diz respeito ao clima subtropical e temperado. Dessa forma, o seu cultivo no Brasil acontece principalmente no Sul e Sudeste, sendo que a sua produção em nível comercial é realizada em nove estados brasileiros, 
conforme Camargo Filho, Mazzei e Alves (2003), os maiores são São Paulo, Rio Grande do Sul, Paraná e Rio de Janeiro.

O método de análise inicia-se então com a geração de alternativas por meio da captura de imagens, do fruto, com o auxílio de uma câmera fotográfica digital. Para possibilitar o estudo das formas e cores das partes que compõe o modelo biológico, foi necessário realizar as fotografias de vários ângulos, mas apenas alguns serão apresentados de fato neste artigo. Primeiramente com o fruto inteiro, da maneira como foi apanhando do pé (Figura 2).

Figura 2 - Fotografia do Caqui Inteiro

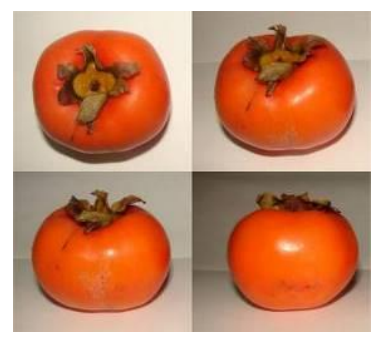

Fonte: Elaborado pelos autores, com base na pesquisa realizada.

Além do fruto, foi analisada também a folha do caquizeiro, pois ela apresenta visualmente características interessantes a serem exploradas para a geração das alternativas. Nas fotografias tiradas pode ser observada a diversidade de coloração das folhas, sendo que as em tons de laranja e vermelho estão se preparando para cair do pé (Figura 3).

Figura 3 - Fotografia folhas do Caquizeiro

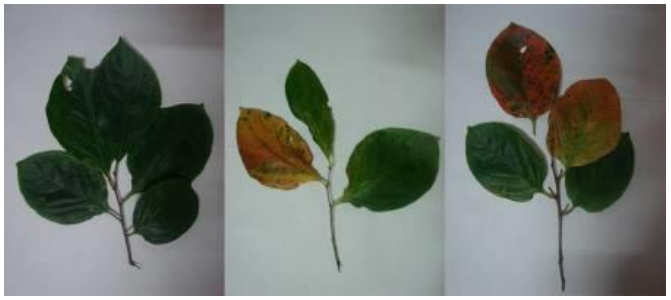

Fonte: Elaborado pelos autores, com base na pesquisa realizada.

Não sendo suficiente a análise a olho nu do objeto, parte-se então para a análise com o auxílio de um microscópio. Conforme, Hsuan-Na (2002), "[e]lementos ou detalhes minuciosos ou microscópios não podem ser ignorados apesar das dimensões reduzidas.". Para realizar este processo foi utilizado um Microscópio USB Digital, onde a taxa de ampliação que varia entre 20 e 400 vezes, possibilitando a captura das imagens do objeto de estudo.

O fruto colhido para a análise microscópica é uma espécie que de Caqui que possui sementes. Neste caso, o modelo biológico pode ser dividido e cada parte que o compõe pode ser analisada, tais como, casca, polpa, semente, folha, assim como o encontro entre a polpa e a semente. Primeiramente analisou-se a casca externa do fruto, ela possui uma textura uniforme e com poucas rugosidades e coloração mais viva. Posteriormente partiu-se o fruto ao meio para que se pudesse analisar seu interior, a polpa. Com isso, foi possível observar a variedade de texturas e fibras encontradas em apenas uma amostra, predominam tons mais amarelados e alguns pontos mais escuros onde a polpa já está começando a amadurecer.

Outra parte que não pode ficar de fora da análise os elementos que mantem o fruto pendurado ao pé, chamadas de pedúnculo e sépala. Aproximando estes 
elementos no microscópio é possível observar texturas variadas, em tons de verde e marrom (Figura 4).

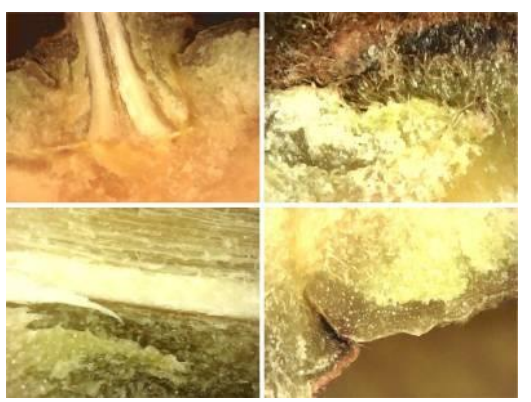

Figura 4 - Fotografia Microscópica | Pedúnculo e Sépala Fonte: Elaborado pelos autores, com base na pesquisa.

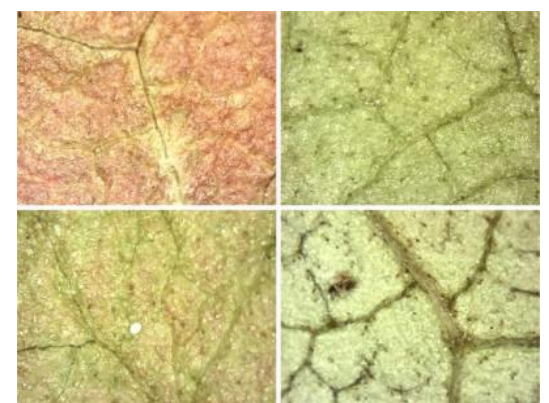

Figura 5 - Fotografia Microscópica | Folhas Caquizeiro Fonte: Elaborado pelos autores, com base na pesquisa.

Finalmente é realizada a análise microscópica da folha do caquizeiro, esta apresenta textura com nervuras e cores diversas, que varia do laranja ao verde, dependendo do estado da folha que foi fotografada (Figura 5). Feita a coleta de imagens do caqui e de suas partes, tanto a olho nu, como microscopicamente, cabe então a aplicação dos estudos de Design de Superfície em relação ao material escolhido, a fim de elaborar padrões que irão gerar estampas para a indústria têxtil, a partir da leitura das texturas, formas e cores que a natureza nos propõe na análise em questão.

\subsection{Análise e discussão dos resultados}

A partir das imagens coletadas, teve início a parametrização das mesmas, a análise das formas, cores e posteriormente a criação dos padrões. Gerando, sugestões de estampas desenvolvidas por meio da análise biônica, para a aplicação na indústria têxtil.

Foram considerados alguns fatores relevantes para a elaboração do projeto de Design de Superfície, dentre eles a ordem estética da imagem, assim como a presença de elementos visualmente atraentes e com possibilidade de estudo e exploração para a geração dos padrões. A amostragem das imagens para a realização dos estudos foi feita a partir da verificação de que muitas possuíam afinidade de formas e cores, sendo então divididas em dois grupos de estudo: o caqui e a folha

\subsubsection{O caqui}

Para o primeiro estudo foram escolhidas as fotos feitas a olho nu, da parte externa e interna do Caqui. Estas serviram como ponto de partida para o estudo das formas e das cores. Para extrair do elemento natural as formas, foi utilizada uma técnica que Rubim (2010) propõe. Através dela, o processo criativo pode ser abordado de forma tradicional, por meio de uma imagem escolhida se fazem cópias preto e branco. A partir do posicionamento livre de um papel manteiga sobre as imagens, vai sendo desenhado tudo o que visualmente se mostra interessante, realizando assim uma coleta das formas do objeto de estudo. A figura 6 mostra o resultado dessa técnica aplicado à imagem do Caqui. 
Figura 6 - Estudo das Formas | Caqui

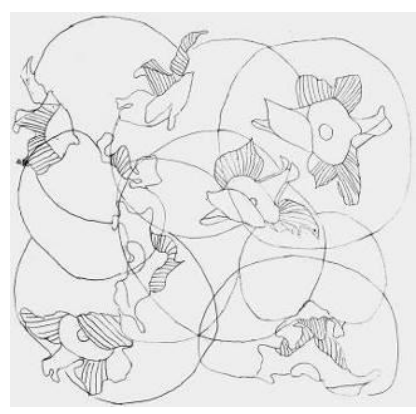

Fonte: Elaborado pelos autores, com base na pesquisa realizada.

As formas obtidas possuem traços orgânicos que geram uma unificação no desenho, já que os elementos de estudo possuem formas semelhantes, que foram agrupadas na elaboração da composição.

Em seguida, passou-se à escolha da cartela de cores, com a aplicação da ferramenta Filtro de Textura - Steined Glass, do programa Photoshop (Figura 7), nas imagens escolhidas do Caqui. Com base no resultado da aplicação desse filtro, foi selecionada uma gama de cores (Figura 8), com sua escala CMYK e também o Pantone, para em seguida poderem ser aplicadas corretamente e com fidelidade na indústria.

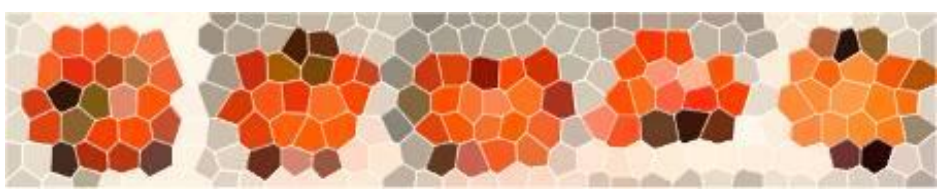

Figura 7 - Aplicação do Filtro Steined Glass | Caqui

Elaborado pelos autores, com base na pesquisa realizada.

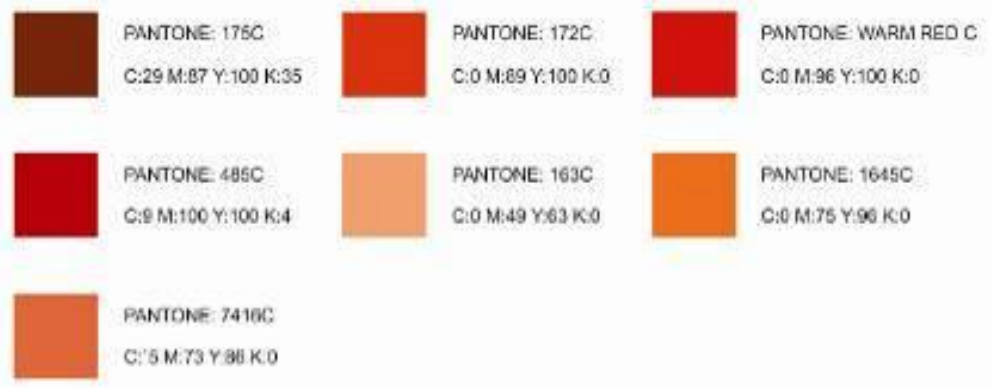

Figura 8 - Gama de Cores Caqui | Escala CMYK e PANTONE

Fonte: Elaborado pelos autores, com base na pesquisa realizada.

Para a elaboração dos módulos de repetição para a elaboração da padronagem, as formas extraídas das fotografias com a utilização de papel manteiga. Foram vetorizadas, com o auxílio do programa Corel Draw. Para que o módulo possa gerar uma repetição contínua, foi aplicada a técnica "dropp" de rapport, porposta também por Rubim (2010). A técnica consiste em utilizar um desenho feito dentro de um quadrado, neste caso já vetorizado, dividir este quadrado em quatro partes (figura 9). 
Figura 9 - Divisão do Desenho | Caqui
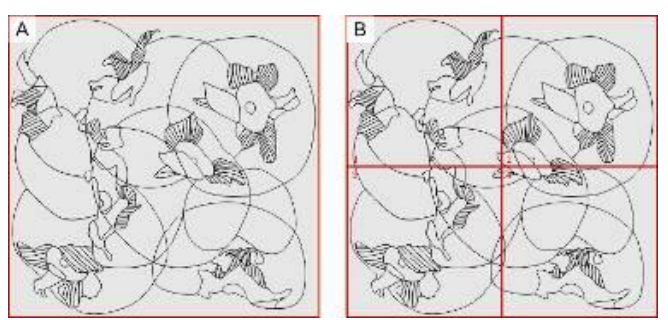

Fonte: Elaborado pelos autores, com base na pesquisa realizada.

Com o desmembramento pás 4 partes em que o quadrado foi dividido, é feito um reposicionamento em uma ordem lógica, a fim de completar os espaços que ficaram em branco nas extremidades de cada parte (Figura 10), possibilitando a finalização do módulo de maneira que a repetição ocorra de maneira em que haja continuidade das formas.

Figura 10 - Módulo com espaços completados | Caqui

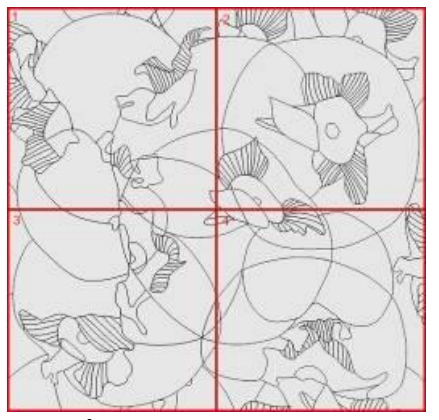

Fonte: Elaborado pelos autores, com base na pesquisa realizada.

Com o módulo finalizado foi possível fazer a aplicação das cores, já selecionadas no processo de parametrização (figura 8). Avaliando as possíveis combinações de cores, foi possível agrupar os tons mais suaves com tons terrosos. (Figura 11)

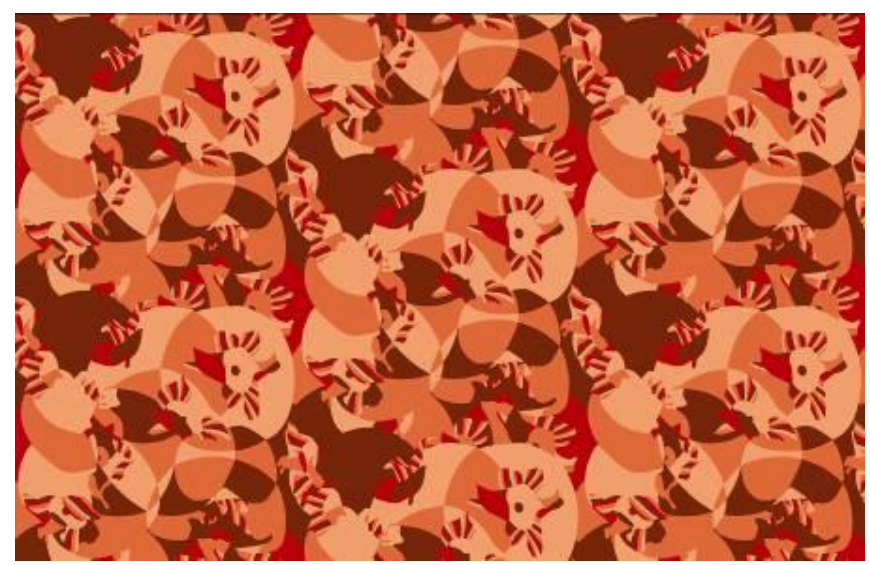

Figura 11 - Padrão 01 | Caqui

Fonte: Elaborado pelos autores, com base na pesquisa realizada.

\subsubsection{A folha}

O segundo elemento que teve as imagens selecionadas, como possibilidade de geração de padrões foi a folha do caquizeiro. As fotografias selecionadas para este 
estudo são tanto as que a representam "a olha nu", quanto as obtidas por meio de microscópio (Figura 12).

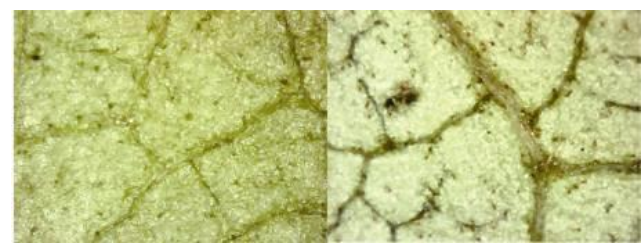

Figura 12 - Escolha das fotografias microscópicas | Folhas

Fonte: Elaborado pelos autores, com base na pesquisa realizada.

Aplicando a mesma técnica utilizada para a criação da padronagem anterior, foi obtido o resultado. (Figura 13)

Figura 13 - Estudo das Formas | Folhas

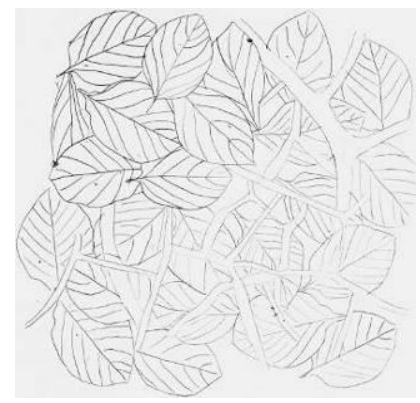

Fonte: Elaborado pelos autores, com base na pesquisa realizada.

As formas extraídas, também possuem traços orgânicos, como no estudo anterior, e a semelhança das mesmas faz com que a composição total possua uma unidade visual. A técnica para obtenção das cores for a mesma que na padronagem do fruto e os resultados podem ser observados nas figura 14 e 15 .

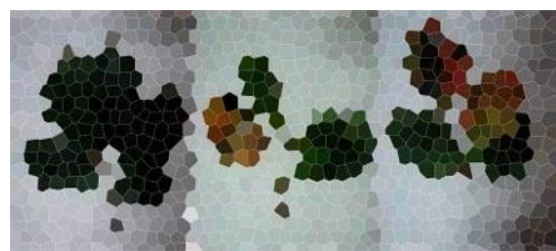

Figura 14 - Aplicação do Filtro Steined Glass | Folha Microscópio

Fonte: Elaborado pelos autores, com base na pesquisa realizada.

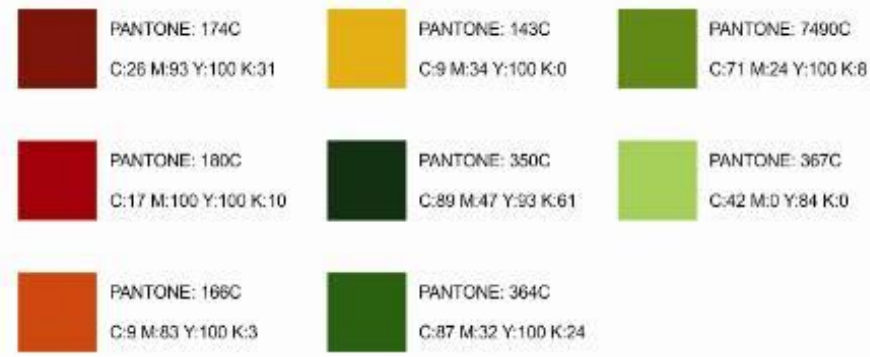

Figura 15 - Gama de Cores Folhas | Escala CMYK e PANTONE

Fonte: Elaborado pelos autores, com base na pesquisa realizada. 
Para a elaboração do módulo, foi selecionada, neste caso, apenas uma parte da imagem resultante da busca de referências visuais (delimitada pela linha vermelha) que visualmente possuía linhas e formas mais uniformes, e a mesma foi vetorizada no Corel Draw (Figura 16).

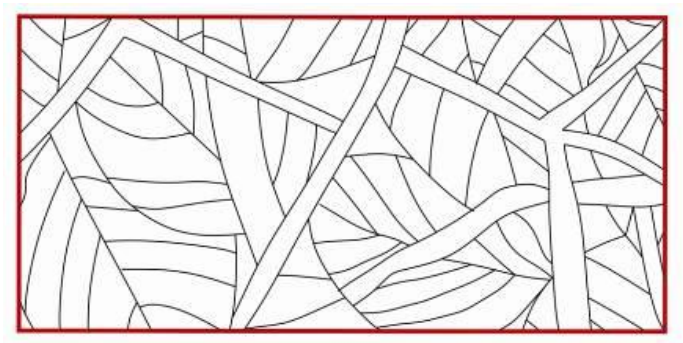

Figura 16 - Vetorização das Formas | Folha

Fonte: Elaborado pelos autores, com base na pesquisa realizada.

A partir desse desenho, foi aplicada outra técnica proposta por Rubim (2010), denominada rapport, que consiste em: selecionar um desenho, centralizá-lo em uma folha, deixando as bordas livres. Posteriormente são feitas dobraduras para que se possa dar continuidade ao desenho, criando um módulo que possa ser repetido, chegando-se em um resultado final, apresentado na figura 17.

Figura 17 - Padrão 02 | Folhas

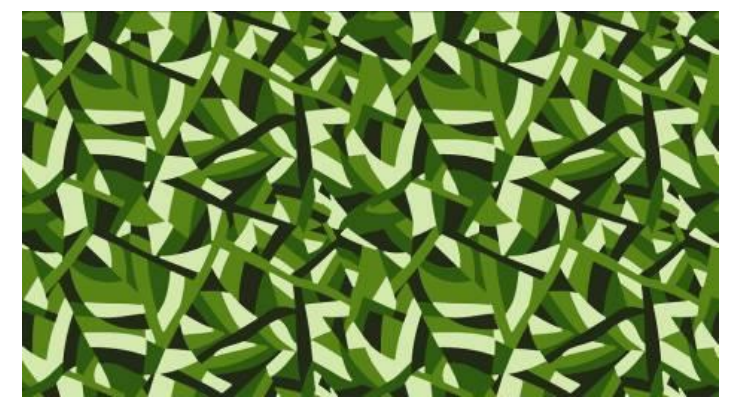

Fonte: Elaborado pelos autores, com base na pesquisa realizada.

\section{CONSIDERAÇÕES FINAIS}

Partindo dos estudos do Design de Superfície e a sua relação com a biônica, bem como do conhecimento da importância do design para a indústria têxtil, tornouse possível desenvolver este estudo projetual. Ao final deste, com a combinação de formas e cores, foram elaboradas duas padronagens diferentes e originais. Outras possibilidades podem ser criadas a partir da mesma fonte criativa, neste caso, a fruta e as folhas do caquizeiro. Com isso, pode-se verificar então, que o resultado final dependerá de como um determinado elemento que serve ao designer como fonte de inspiração para a criação de uma padronagem é estudado e analisado pelo designer. Por isso este projeto abre caminho para os profissionais e estudantes da área, pensarem como um elemento inusitado pode servir para a elaboração de um projeto de design de superfície, e contribuir para exercitar e desenvolver a criatividade.

\section{REFERÊNCIAS}

BASSO, Liliane; RUTHSCHILLING, Evelise Anicet. Possibilidades Expressivas e Combinatórias de Biomorfismo no Design de Superfície: Caso Caranguejo. Disponível 
em: <http://blogs.anhembi.br/congressodesign/anais/artigos/69594.pdf>. Acessado em 27 de Fevereiro de 2012.

BERTOLINI, Juliana. Moda da Natureza: Inter-relações entre Moda e Biônica. 2009. 145f. Dissertação. Mestrado de Educação, Arte e História da Cultura- Universidade Presbiteriana Mackenzie, São Paulo, 2009.

CALDERÓN, Gracia Casaretto. 0 processo criativo do designer gráfico na elaboração de estampas para uma coleção de moda. Disponível em: <http://blogs.anhembi.br/congressodesign/anais/artigos/69559.pdf >. Acessado em: 01 de Agosto de 2011.

CHATAIGNIER, Gilda. Fio a fio: tecidos, moda e linguagem. São Paulo: Estação das Letras Editora, 2006.

DETANICO, Flora Bittencourt; TEIXEIRA,, Fábio Teixeira, SILVA, Tânia L. K. da. A Biomimética como Método Criativo para o Projeto de Produto. Disponível em: <http://www.pgdesign.ufrgs.br/designetecnologia/index.php/det/article/view/52/33> .Acessado em: 10 de Março de 2012.

DOCZI, Gyorgy. 0 poder dos limites: harmonias e proporções na natureza, arte e arquitetura. São Paulo: Mercuryo, 2006. 149p.

EDAGI, Fernando Kazuhiro; Kluge, Ricardo Alfredo. Remoção de adstringência de caqui: um enfoque bioquímico, fisiológico e tecnológico. Disponível em: < http://www.scielo.br/pdf/cr/v39n2/a46v39n2.pdf>. Acessado em: 05 de Maio de 2012.

LEVINBOOK, Miriam. Designde Superfície: técnicas e processos em estamparia têxtil para produção industrial.2008. 105f. Dissertação (Mestrado em Design) - Programa de Pós-Graduação Stricto Sensu em Design, Universidade Anhembi Morumbi, São Paulo, 2008. Disponível em: <http://www.anhembi.br/mestradodesign/pdfs/miriam.pdf>. Acessado em: 05 de Março de 2012.

HSUAN-NA, Tai. Sementes do Cerrado e Design Contemporâneo. Gioânia: Ed. Da UCG, 2002. 219 p.

MINUZZI, Reinilda; OLIVEIRA, Monique Aline A. de. Design de Superfície: caminhos e possibilidades entre a arte, a tecnologia e o design. Disponível em: $<$ http://www.modavestuario.com/395designdesuperficie.pdf $>$. Acessado em: 05 de Março de 2012.

MUNARI, Bruno. Das coisas nascem coisas. 2. Ed. São Paulo: Martins Fontes, 2008.

PEREIRA, Priscila Zavadil; RUTHSCHILLING, Evelise Anicet; SILVA, Régio Pierre. Design de superfície: cultura iconográfica como referência para a estamparia têxtil. Disponível em: <http://www.modavestuario.com/395designdesuperficie.pdf >. Acessado em: 09 de Março de 2012.

PEZZOLO, Dinah Bueno. Tecidos: história, tramas, tipos e usos. São Paulo: Editora SENAC São Paulo, 2007.

RUBIM, Renata. Desenhando a superfície. 2. ed., rev. atual. São Paulo: Edições Rosari, 2010.

RÜTHSCHILLING, Evelise Anicet. Design de superfície. Porto Alegre: Editora da Universidade Federal do Rio Grande do Sul, 2008. 